\title{
Aggregation and conformational changes of bovine $\beta$-lactoglobulin subjected to dynamic high-pressure microfluidization in relation to antigenicity
}

\author{
J. Z. Zhong, ${ }^{*}$ W. Liu, ${ }^{*}$ C. M. Liu, ${ }^{, 1}$ Q. H. Wang, † T. Li, ${ }^{*}$ Z. C. Tu, ${ }^{\star}$ S. J. Luo, ${ }^{*}$ X. F. Cai, ${ }^{,}$and Y. J. Xu \\ *State Key Laboratory of Food Science and Technology, Nanchang University, Nanchang 330047, China \\ †Chinese Academy of Tropical Agricultural Sciences, Danzhou, Hainan 571737, China
}

\begin{abstract}
Our previous research indicated that dynamic highpressure microfluidization (DHPM) had a significant effect on the antigenicity of $\beta$-lactoglobulin ( $\beta$-LG). In this study, aggregation and conformational changes subjected to DHPM (0.1-160 MPa) were investigated in relation to antigenicity. When DHPM pressure increased from 0.1 to $80 \mathrm{MPa}$, disaggregation of $\beta-\mathrm{LG}$ samples and partial unfolding of the molecule were accompanied by an increase in $\beta-\mathrm{LG}$ antigenicity, which was reflected in the decrease of particle size, increase of free sulfhydryl (SH) contents and $\beta$-strands contents, and slight exposure of aromatic amino acid residues. At pressures above $80 \mathrm{MPa}$, the reaggregation of $\beta$-LG may contribute to the decrease in antigenicity, which was reflected by an increase in particle size, the formation of aggregates, a decrease of in $\mathrm{SH}$ and $\beta$-strands contents, and slight changes in aromatic amino acid residues. Aggregation and conformational changes of $\beta$-LG under DHPM was related to its antigenicity.

Key words: $\beta$-lactoglobulin, antigenicity, dynamic high-pressure microfluidization (DHPM), protein conformation
\end{abstract}

\section{INTRODUCTION}

Prevention of milk allergies has become a clinical public health concern and constitutes a major challenge for the dairy industry. $\beta$-Lactoglobulin is the major whey protein in the milk of many mammals and is considered to be the major cow milk allergen; that is, the protein most frequently and intensively recognized by human $\operatorname{IgE}$ (Wal, 2002). The epitopes of $\beta$-LG have been extensively studied, and these studies have demonstrated that epitopes of $\beta$-LG are widely spread along the 162 AA (Clement et al., 2002). Many allergenic epitopes are spread throughout the $\beta$-LG structure, the changes in which may directly influence the antigenicity of the

Received January 11, 2012.

Accepted April 5, 2012.

${ }^{1}$ Corresponding author: chengmeiliu@yahoo.com.cn protein (Sélo et al., 1999a). Current research focuses primarily on linear epitopes (Sélo et al., 1999a; Jarvinen et al., 2001; Clement et al., 2002; Ametani et al., 2003), whereas information is lacking on the aggregation and conformational changes as a research emphasis for the antigenicity of $\beta$-LG.

In recent years, many reports have described the antigenicity changes of $\beta-L G$ induced by numerous treatments, such as heat treatment, enzymatic hydrolysis, and physical treatment. According to previous studies, heat treatment (above $90^{\circ} \mathrm{C}$ ) may be applied to reduce the antigenicity of $\beta-\mathrm{LG}$, whereas heating below $90^{\circ} \mathrm{C}$ could increase the antigenicity of $\beta$-LG (Kleber et al., 2004; Kleber and Hinrichs, 2007). It was observed that enzymatic hydrolysis could reduce the antigenicity of $\beta-L G$ (Zheng et al., 2008). In addition, some physical treatments have become a focus for research in the antigenicity of $\beta$-LG. For example, Grar et al. (2009) used microwave irradiation to treat $\beta-\mathrm{LG}$ and found that it could reduce the antigenicity of $\beta$-LG. Kleber et al. (2007) observed that high hydrostatic pressure treatment at 400 and $600 \mathrm{MPa}$ could increase the antigenicity of $\beta$-LG.

In our previous work, we found that an emerging dynamic high-pressure technology, dynamic high-pressure microfluidization (DHPM), had a significant effect on the antigenic response of $\beta$-LG: DHPM-modified $\beta$-LG showed a remarkable increase of antigenicity when treated below $80 \mathrm{MPa}$. As pressure exceeded $80 \mathrm{MPa}$, the antigenicity decreased (Zhong et al., 2011). The DHPM method possesses combined forces of high-velocity impact, high-frequency vibration, instantaneous pressure drop, intense shear, cavitation, and ultrahigh pressure up to $200 \mathrm{MPa}$ with a short treatment time (less than $5 \mathrm{~s}$ ) and continuous operation (Liu et al., 2009b). Recently, DHPM has been applied to the reduction in microbial populations in dairy products (Feijoo et al., 1997; Moroni et al., 2002), production of fat substitute (Paquin, 1999), preparation of cheese (Tunick et al., 2000; Kheadr et al., 2002), and improvement of the quality of milk (Lanciotti et al., 2004). Furthermore, it was observed that changes in functional properties (e.g., solubility, foaming, and emulsifying) of 
whey protein were related to the aggregation changes induced by DHPM (Liu et al., 2011).

Accordingly, whether the antigenicity changes of $\beta$-LG treated by DHPM are also due to the changes of aggregation or conformation is still uncertain. According to reports, allergenic epitopes are related to the $\beta-L G$ structure (Sélo et al., 1999a). We hypothesized that when the aggregation and conformational changes of $\beta$-LG are induced by DHPM, as reflected by changes in particle size, sulfhydryl (SH) content, and secondary and tertiary structure, those epitopes may be exposed or buried, which directly influences the antigenicity of $\beta$-LG. However, very limited data are available on the relationships among antigenicity, aggregation, and conformational changes. The aim of this work was to evaluate the aggregation and conformational changes of $\beta$-LG subjected to DHPM and to relate these changes to the antigenicity of $\beta$-LG.

\section{MATERIALS AND METHODS}

\section{Materials and Reagents}

Bovine $\beta$-LG (L3908) was obtained from Sigma-Aldrich Chemical Co. (St. Louis, MO). All other materials and reagents were of analytical grade, and solutions were prepared in double-distilled water.

\section{DHPM Treatment}

The $\beta$-LG solution $(1 \mathrm{mg} / \mathrm{mL})$ was treated (3 passes each) at pressures of $0.1,40,80,120$, and $160 \mathrm{MPa}$, respectively, in a Microfluidizer processor (model M-7125, Microfluidics, Newton, MA). Samples were collected and then stored immediately at $4^{\circ} \mathrm{C}$ for assay (Zhong et al., 2011).

\section{Determination of Particle Size Distribution}

Particle size distributions were determined with a laser scattering Mastersizer S (380/ZLS, Nicomp International, Orlando, FL). The Nicomp 380, based on dynamic light scattering (DLS), provides accurate particle size distribution (PSD) results to $1 \mathrm{~nm}$. Samples were diluted approximately 1/1,000 with deionized water in the sample dispersion unit under stirring at 1,500 rpm (Liu et al., 2011).

\section{Atomic Force Morphological Analysis}

Dispersions of $\beta$-LG ( $1 \mathrm{mg} / \mathrm{mL})$ were investigated using an AJ-V atomic force microscope (AFM; Aijian, Shanghai, China). Each dispersion $(10 \mu \mathrm{L})$ was deposited onto a freshly cleaved mica surface and subsequently dried in a desiccator. The scan rate was set at $1 \mathrm{~Hz}$ (Oboroceanu et al., 2010).

\section{Determination of Free SH Contents}

Free SH contents were analyzed using Ellman's reagent (Ellman, 1959; Sava et al., 2005). Free SH contents for $\beta$-LG were obtained by adding $\beta$-LG solutions ( $1 \mathrm{mg} /$ $\mathrm{mL}$ ) treated for 3 passes each under different pressure in $0.1 \mathrm{M} \mathrm{pH} 8.0$ sodium phosphate buffer. The above solutions were incubated at $25^{\circ} \mathrm{C}$ for $1 \mathrm{~h}$; then, $50 \mu \mathrm{L}$ of each sample was extracted from the solutions after $1 \mathrm{~h}$ and $25 \mu \mathrm{L}$ of $0.01 M 5,5^{\prime}$-dithiobis-2-nitrobenzoic acid (DTNB) was added to it. The solution was then diluted to $10 \mathrm{~mL}$ and UV absorbance at $412 \mathrm{~nm}$ was measured at $25^{\circ} \mathrm{C}$. The $\mathrm{SH}$ contents were calculated by the use of extinction coefficient of 2-nitro-5-thiobenzoate (NTB) at $412 \mathrm{~nm}, 13,600 M^{-1} \mathrm{~cm}^{-1}$, expressed as micromoles per gram of protein.

\section{Measurements of Intrinsic Fluorescence and UV Absorption Spectra Analysis}

Fluorescence analyses were performed for $\beta$-LG samples treated at different pressures. Fluorescence measurements were carried out in a Hitachi spectrofluorimeter (F-4500, Hitachi, Tokyo, Japan) using 10-mm ${ }^{2}$ quartz cells and a protein concentration of $1 \mathrm{mg} / \mathrm{mL}$ in phosphate buffer $(10 \mathrm{mM}, \mathrm{pH} 7.0)$. The excitation wavelength was $280 \mathrm{~nm}$; the emission spectrum was scanned from 300 to $450 \mathrm{~nm}$, using 5-nm bandwidth, with excitation and emission slits of 2.5 and $5.0 \mathrm{~nm}$, respectively, and at a scan speed of $240 \mathrm{~nm} / \mathrm{min}$ (de la Hoz and Netto, 2008).

The UV absorption spectra of $\beta$-LG were measured by using a UV-visible 2510PC spectrophotometer (Shimadzu, Kyoto, Japan). The UV absorption spectra were scanned from 200 to $360 \mathrm{~nm}$.

\section{Circular Dichroism Spectroscopy}

Circular dichroism (CD) analyses were run for $\beta-\mathrm{LG}$ treated by DHPM, as modified by Chen et al. (2005). The CD spectra of $\beta$-LG at $1 \mathrm{mg} / \mathrm{mL}$ (for near UV) and $0.1 \mathrm{mg} / \mathrm{mL}$ (for far UV) in $10 \mathrm{~m} M$ sodium phosphate buffer, $\mathrm{pH}$ 7.0, were collected using a MOS-450 spectropolarimeter (French Bio-Logic SAS, Claix, French), at $22^{\circ} \mathrm{C}$. Cylindrical quartz cuvettes with path lengths of 1.0 and $0.1 \mathrm{~cm}$ were used for collecting data in the nearUV (250-350 nm) and far-UV (185-250 nm) regions, respectively. The scanning conditions were 0.2 and 1 $\mathrm{nm}$ step resolution for near and far-UV, respectively; both scans were performed using a $100 \mathrm{~nm} / \mathrm{min}$ scan rate, $1.0 \mathrm{~nm}$ of bandwidth and 4 scans, corrected by 
subtracting the buffer baseline spectrum. The CD data were expressed in terms of mean residual ellipticity $([\boldsymbol{\theta}]$; degree $\left.\mathrm{cm}^{2} \mathrm{dmol}^{-1}\right)$. Structure predictions from CD spectra were obtained using the Contin LL program (de la Hoz and Netto, 2008).

\section{Statistical Analysis}

The one-way ANOVA test for significant effects of treatments and assays was determined using SPSS 12.0.1 (SPSS Inc., Chicago, IL). Main effect differences were considered significant at $P \leq 0.05$. Mean separations were determined by Tukey's procedure for multiple comparisons. All experiments (CD analysis 4 times) were analyzed in triplicate.

\section{RESULTS AND DISCUSSION}

\section{Particle Size and Morphological Analysis of $\beta-L G$}

The effect of DHPM treatment on the particle size distribution was determined by assaying particle size distribution and average particle size at different pressures. As shown in Figure 1a, the average particle size of $\beta$-LG treated at $0.1 \mathrm{MPa}$ was $402.2 \mathrm{~nm}$ with a range from $50 \mathrm{~nm}$ to $2 \mu \mathrm{m}$. As reported by other studies, the radius of the $\beta$-LG monomer is about 2 to $3 \mathrm{~nm}$, based on the crystal structures (Aymard et al., 1999). The DLS and AFM data suggested that the $\beta$-LG particles treated at $0.1 \mathrm{MPa}$ were aggregated. As the pressure increased, the average particle size decreased $(175.9 \mathrm{~nm}$ at $80 \mathrm{MPa}$ ) and the distribution of particle size narrowed. It was consistent with the results of AFM, as shown in Figure 1b (panels 1-3). According to the study of Liu et al. (2011), DHPM treatment can induce disaggregation of whey proteins, resulting in decreased particle size. However, it was clear that the average particle size increased and the distribution of particle size extended as the treatment pressure increased. Particle size increased to $182.1 \mathrm{~nm}$ at $160 \mathrm{MPa}$. It was indicated that $\beta$-LG did reaggregate. Similar results were observed from the AFM analysis (Figure 1b, panels 4 and 5). It is clear from Figure $1 b$ that $\beta$-LG aggregation particles were reaggregated and formed larger aggregates when subjected to pressures of $80 \mathrm{MPa}$. It was reported that many treatments could induce the aggregation process of $\beta$-LG. For example, Oboroceanu et al. (2010) using AFM analysis also observed the aggregation process of $\beta$-LG after heating treatment at different times.

\section{Analysis of SH Content of $\beta-L G$}

The free SH contents of DHPM-treated $\beta$-LG samples are shown in Figure 2. Treatment with DHPM initially increased the free $\mathrm{SH}$ contents of $\beta$-LG. The pressure treatment used had a significant effect on free SH contents $(P<0.05)$. One $\beta$-LG molecule has 1 free $\mathrm{SH}$ group, and the content of the free $\mathrm{SH}$ group is 54.6 $\mu \mathrm{mol} / \mathrm{g}$ of protein (Sava et al., 2005). In our study, the SH group content of 0.1 MPa-treated samples was found to be $32.3 \mu \mathrm{mol} / \mathrm{g}$ of protein, indicating that the
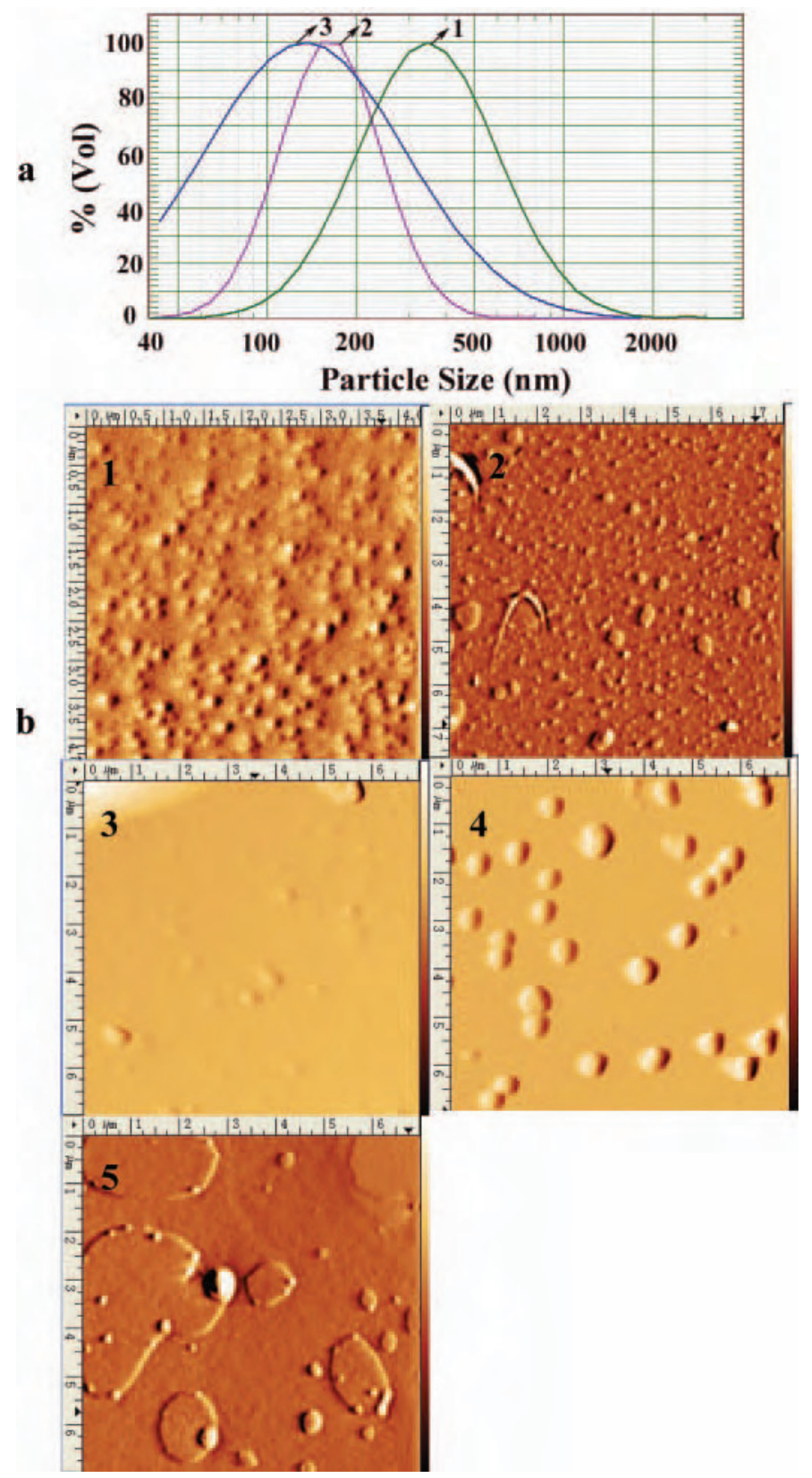

Figure 1. (a) Particle size distributions of $\beta-\mathrm{LG}$ solutions treated at different dynamic high-pressure microfluidization (DHPM) pressures; 1 to 3 represent pressures of $0.1,80$, and $160 \mathrm{MPa}$, respectively; (b) atomic force microscope images of $\beta$-LG at different DHPM pressures; 1 to 5 represent pressures of $0.1,40,80,120$, and $160 \mathrm{MPa}$, respectively. Color version available in the online PDF. 
protein may be aggregated. The result was consistent with that of the DLS and AFM data. After treatment of $\beta$-LG at 40 and $80 \mathrm{MPa}$, the $\mathrm{SH}$ content was increased to 34.5 and $36.6 \mu \mathrm{mol} / \mathrm{g}$, respectively, values lower than the reported $54.6 \mu \mathrm{mol} / \mathrm{g}$ of protein (Sava et al., 2005). Thus, the new increased SH group treated by DHPM did not result from cleavage of a disulfide (SS) bond. The exposure of SH groups was more pronounced at lower pressures, possibly because of the disaggregation of $\beta-L G$ aggregates. In addition, the change in the number of reactive SH group might arise from the conformational change of the $\beta$-LG molecule. For example, at $80 \mathrm{MPa}$, the $\beta$-LG molecule became more unstable, leading to an increase in the frequency of exposure of the free SH group. However, the content did not increase to $54.6 \mu \mathrm{mol} / \mathrm{g}$ of protein, indicating only partial unfolding of the $\beta-\mathrm{LG}$ molecule. The results were in accordance with that of Monahan et al. (1995), who observed that an increase in SH group content indicated conformational changes of protein.

However, when $\beta$-LG was treated at pressures of 120 and $160 \mathrm{MPa}$, the free $\mathrm{SH}$ content decreased to 35.8 and $33.6 \mu \mathrm{mol} / \mathrm{g}$, respectively. The results were in agreement with Funtenberger et al. (1997). They observed that high pressure induced the decrease of SH content, which was responsible for aggregation of $\beta$-LG by the formation of new S-S bonds through $\mathrm{SH} / \mathrm{S}-\mathrm{S}$ interchange reactions. According to some reports, different treatments had different effects on the $\mathrm{SH}$ content of $\beta$-LG. For example, the free $\mathrm{SH}$ content of $\beta$-LG increased after UV irradiation (Kehoe et al.,

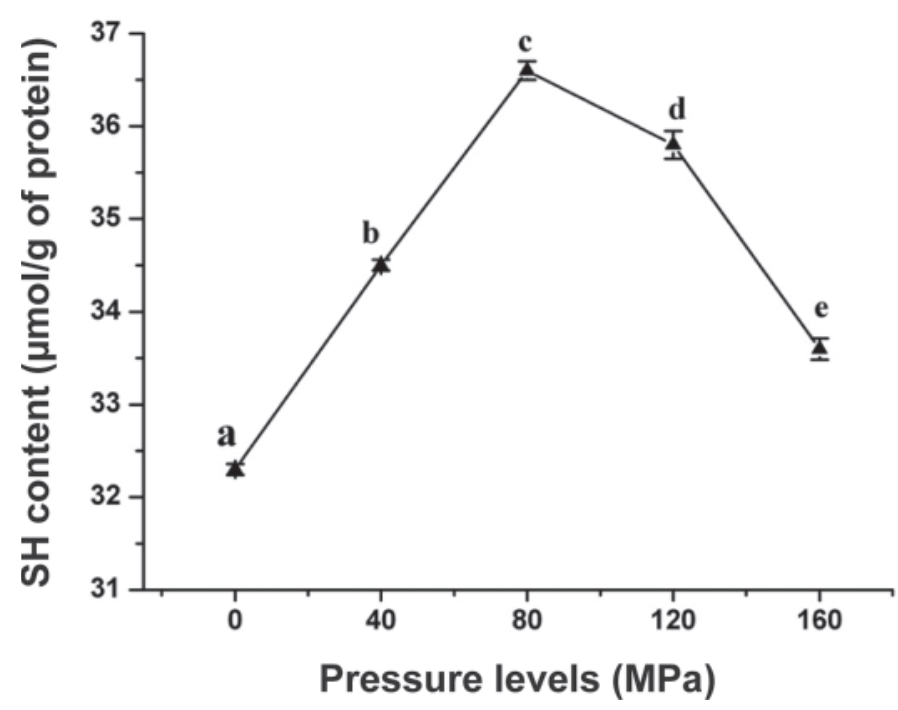

Figure 2. Free sulfhydryl (SH) content of the untreated and the dynamic high-pressure microfluidization (DHPM)-treated $\beta$-LG under pressure ranging from 0.1 to $160 \mathrm{MPa} .{ }^{\mathrm{a}-\mathrm{e}}$ Different letters denote significant differences across different treatments $(P \leq 0.05)$.
2008), whereas when $\beta$-LG was treated by electrolysis, the number of free $\mathrm{SH}$ contents did not change (Matsumoto, 2011). In other cases, the free SH contents of $\beta$-LG was decreased after heating (Sava et al., 2005; Gulzar et al., 2009).

\section{Intrinsic Fluorescence Analysis of $\beta-L G$ Samples}

The fluorescence spectrum of DHPM-treated $\beta$-LG was observed and the results are shown in Figure 3a. It can be noted that DHPM treatment contributed to an increase in relative fluorescence intensity. With DHPM pressure increasing, the relative intensity was increased gradually. According to some reports, an increase in intrinsic fluorescence intensity can cause disaggregation of large protein aggregates (Liu et al., 2011) and unfolding of the $\beta$-LG molecule (Yang et al., 2001). As shown in Figure 3a, a red shift of the spectral peak was not observed, indicating that the protein was not highly unfolded. Thus, the increase in the fluorescence was observed under partial unfolding conditions when $\beta-\mathrm{LG}$ was disaggregated.

\section{UV Absorption Spectra Analysis of $\beta-L G$}

The AA residue responsible for the major absorbance of proteins in the near-UV region is tryptophan (Divsalar et al., 2009). Figure 3b showed the effect of DHPM treatment on the UV absorption spectra of $\beta$-LG. The maximum absorption peak was at $277 \mathrm{~nm}$. The absorption intensity of $\beta-\mathrm{LG}$ treated at $0.1 \mathrm{MPa}$ was 0.9324 at $277 \mathrm{~nm}$. The absorption intensity of $\beta$-LG treated at 40 and $80 \mathrm{MPa}$ increased significantly, and their absorption intensities were 1.0659 and 1.0699, respectively. The increase in absorption intensity was probably caused by the gradual exposure of hydrophobic groups when the aggregates of $\beta$-LG were disaggregated by DHPM. However, when the pressure was increased to 120 and $160 \mathrm{MPa}$, absorption intensity decreased to 0.8790 and 0.8715 , respectively. According to Liu et al. (2009a), the decrease of UV absorption is due to the aggregation of protein under high pressures, consistent with results found in this study.

\section{Near-UV CD Analysis of $\beta-L G$}

The near-UV CD spectrum of $\beta$-LG showed a pattern of negative peaks between 260 and $320 \mathrm{~nm}$ (Figure $4 a)$, which was due to the presence of aromatic residue. $\beta$-Lactoglobulin includes 2 tryptophan residues (Trp 19 and 61), 4 tyrosines (Tyr 20,42, 99, and 102), and 4 phenylalanines (Phe 82, 105, 136, and 151; Divsalar et al., 2009). The Trp residues are often the major determinants of the near-UV CD curve, and the Trp signals 

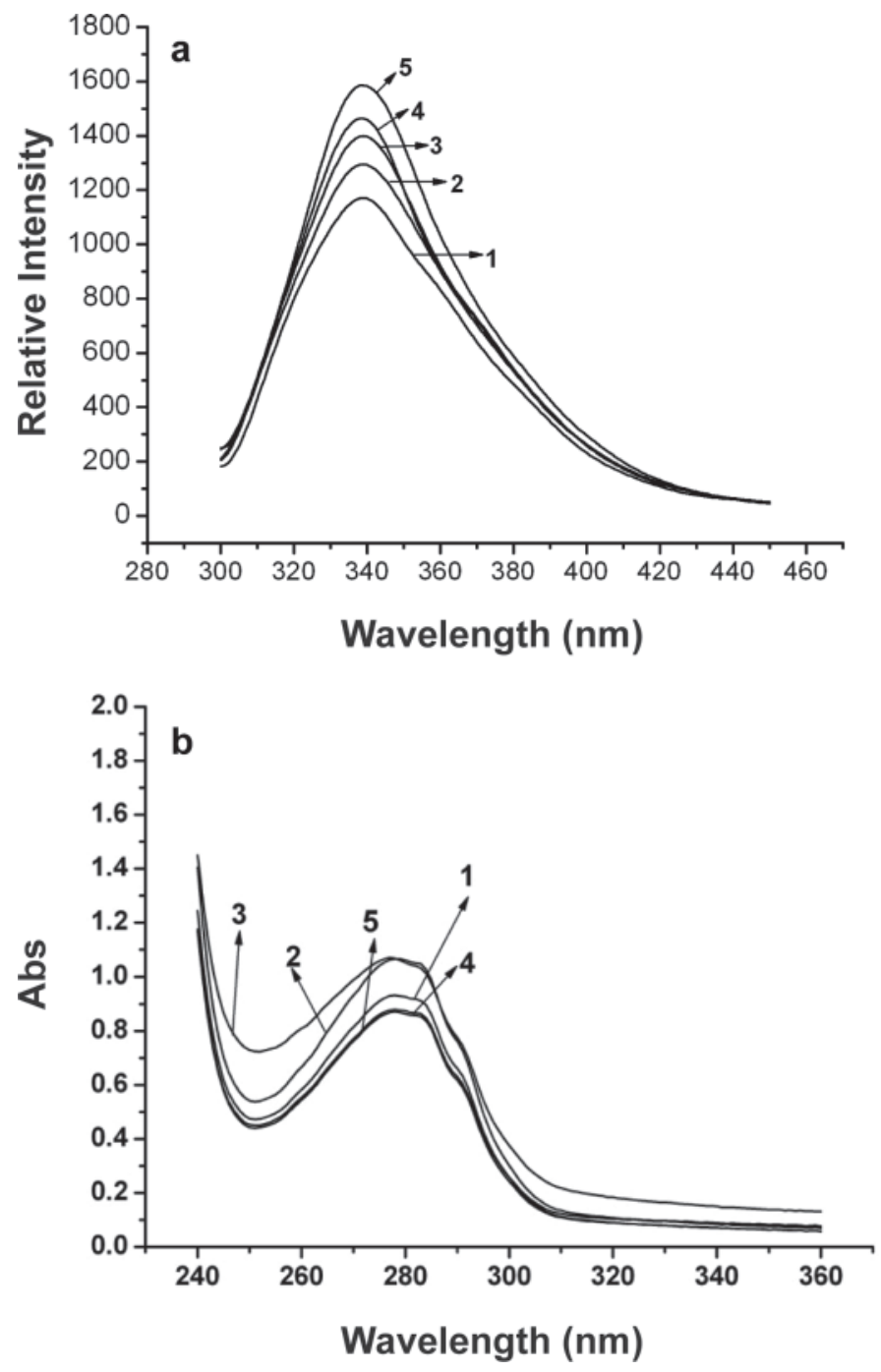

Figure 3. (a) Fluorescence emission spectra of the untreated and the dynamic high-pressure microfluidization (DHPM)-treated $\beta$-LG under pressures varied from 0.1 to $160 \mathrm{MPa} ; 1$ to 5 represent pressures of $0.1,40,80,120$, and $160 \mathrm{MPa}$, respectively; (b) UV absorption spectra of the untreated and the DHPM-treated $\beta$-LG under pressures varied from 0.1 to $160 \mathrm{MPa}$; 1 to 5 represent pressures of $0.1,40,80$, 120 , and $160 \mathrm{MPa}$, respectively.

are generally more intense than those of Tyr and Phe, whereas Phe and Tyr usually do not absorb above 270 $\mathrm{nm}$ and $290 \mathrm{~nm}$, respectively. According to this, the negative bands at 293 and $285 \mathrm{~nm}$ were assigned to asymmetrically perturbed tryptophan residues, whereas the peaks below $280 \mathrm{~nm}$ are likely the result of Phe and Tyr residues (Kelly and Price, 2000).

The near-UV CD spectrum of $\beta-L G$ at different pressure was shown in Figure 4a. It was shown that an increase in mean residual ellipticity at 293 and $285 \mathrm{~nm}$ $\left([\theta]_{293}\right.$ and $\left.[\theta]_{285}\right)$ after $\beta$-LG treated at $80 \mathrm{MPa}$. With DHPM pressure increasing, a decrease in $[\theta]_{293}$ and $[\theta]_{285}$ was observed. It was observed that the position of Trp residues of protein could change and move into more hydrophobic environment, which contributed to the increase of $[\theta]$ (Chang et al., 1978). However, none of the spectra in this study was shifted, indicating that no significant structural changes occurred around the aromatic residues of the $\beta$-LG molecule. The increase of $[\theta]$ was probably caused by the gradual exposure of aromatic residues under partial unfolding conditions when the aggregates of $\beta-L G$ were disaggregated by DHPM. In addition, the decrease in $[\theta]$ indicated that $\beta-L G$ underwent a conformational transition affecting
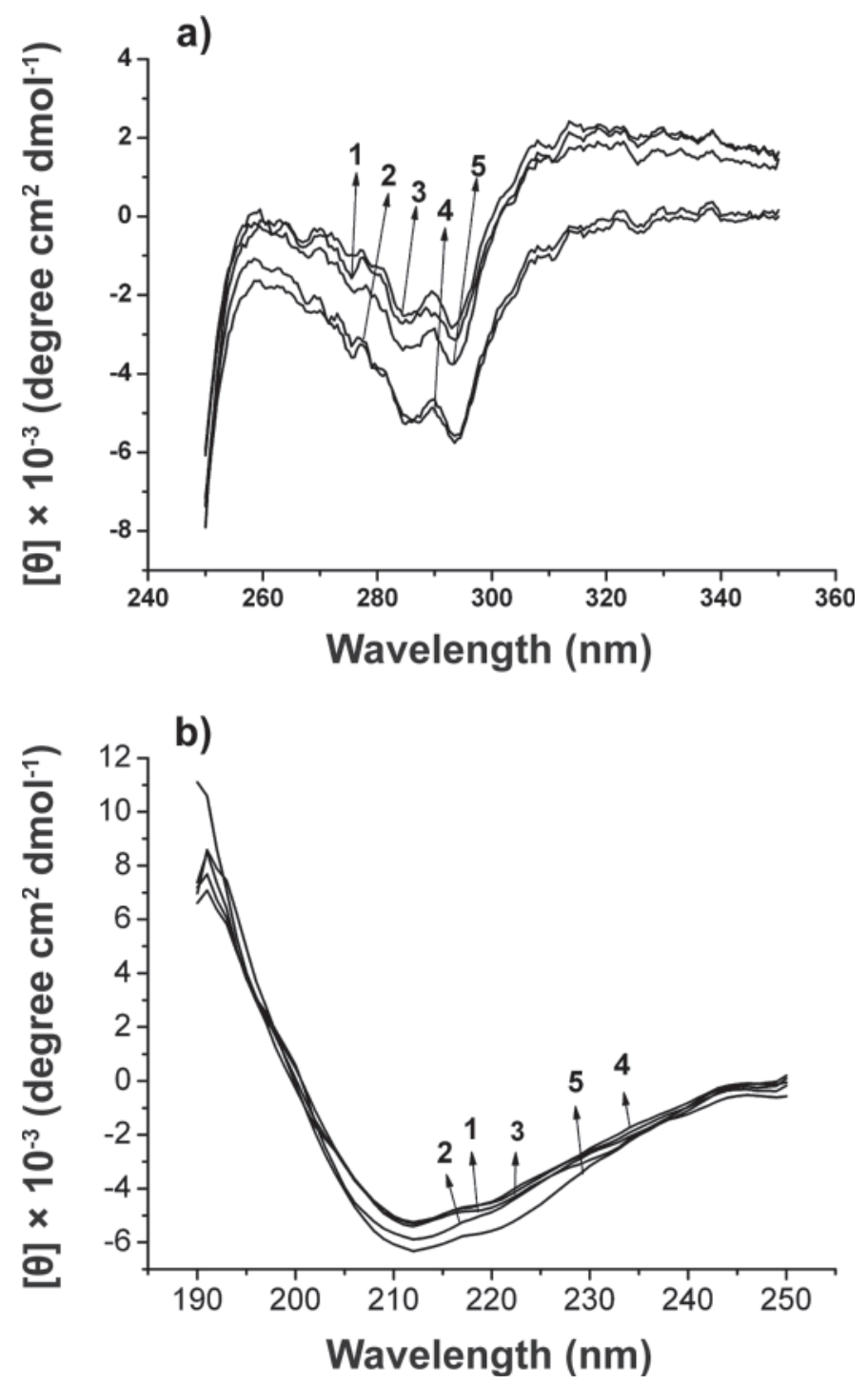

Figure 4. (a) Near-UV circular dichroism (CD) spectra of the untreated and the dynamic high-pressure microfluidization (DHPM)treated $\beta$-LG under pressures ranging from 0.1 to $160 \mathrm{MPa}$; 1 to 5 represent pressures of $0.1,40,80,120$, and $160 \mathrm{MPa}$, respectively; (b) FarUV CD spectra of the untreated and the DHPM-treated $\beta$-LG under pressures varied from 0.1 to $160 \mathrm{MPa} ; 1$ to 5 represent pressures of 0.1 , $40,80,120$, and $160 \mathrm{MPa}$, respectively. $[\theta]=$ mean residual ellipticity. 
its tertiary structure (Matsuura and Manning, 1994; Ptitsyn, 1995). Manderson et al. (1999) also observed the decrease in near-UV CD intensity at $293 \mathrm{~nm}$ after heat treatment of $\beta-\mathrm{LG}$, which indicated that heat treatment induced aggregation of $\beta-\mathrm{LG}$.

\section{Far-UV CD Analysis of $\beta-L G$ Samples}

The far-UV CD spectra of DHPM-treated $\beta$-LG samples are shown in Figure $4 \mathrm{~b}$. As we know, $\beta$-LG is predominantly a $\beta$-sheet protein, consisting of 9 anti-parallel $\beta$-strands and 1 major $\alpha$-helix at the $\mathrm{C}$ terminus of the molecule (Shibayama, 2008). The CD spectra showed a negative extreme around $213 \mathrm{~nm}$, a crossing zero dichroism at $203 \mathrm{~nm}$, and a positive maximum around $195 \mathrm{~nm}$, values that indicate a high content of $\beta$-strands, in accordance with the secondary structure content shown in Table 1. Similar spectra of native-like $\beta$-LG molecules were reported (Matsuura and Manning, 1994; de la Hoz and Netto, 2008). After DHPM treatment, values of negative peaks at $213 \mathrm{~nm}$ gradually decreased, accompanied by an increase in percentage content of $\beta$-strands, from 33.2 to $38.4 \%$ at $80 \mathrm{MPa}$. However, as the pressure level increased, the $\beta$-strand content decreased (37.0 and $32.2 \%$ at 120 and $160 \mathrm{MPa}$, respectively). At all pressure levels, although there were changes in the secondary structure, the spectral change in the far-UV region did not lead the shift of the baseline of the near-UV spectra. Therefore, the secondary structure of $\beta-L G$ slightly changed.

\section{Aggregation and Conformation Changes of $\beta-L G$ Induced by DHPM in Relation to Antigenicity}

Intramolecular bonds of $\beta$-LG maintain the structural integrity of protein and ensure its stability. According to one report (Peyron et al., 2006), the allergenic potential of milk protein depends in part on the integrity of structure epitopes. Under physiological conditions, antibodies can gain access only to the epitopes located at the protein surface; some epitopes will be buried inside the protein molecules and aggregates (Kleber et al., 2004). The aggregation and conformation changes are thus related to the antigenicity of $\beta-\mathrm{LG}$.

Our previous work indicated that DHPM treatment had a significant effect on the antigenicity of $\beta$-LG. As shown in Figure 5, the antigenicity of $117 \mu \mathrm{g} / \mathrm{mL}$ was detected for the $0.1 \mathrm{MPa}$-treated samples. When pressure was increased to $40 \mathrm{MPa}$, the antigenicity increased to $203 \mu \mathrm{g} / \mathrm{mL}$. As pressure increased further, the antigenicity increased to a maximum level of 668 $\mu \mathrm{g} / \mathrm{mL}$ at $80 \mathrm{MPa}$, about 6 times the initial value of the untreated sample. However, the antigenicity of $\beta-\mathrm{LG}$ solutions decreased sharply to 165 and $137 \mu \mathrm{g} / \mathrm{mL}$ after treatment at 120 and $160 \mathrm{MPa}$, respectively, levels slightly higher than the initial value of the untreated sample (Zhong et al., 2011). The present study was undertaken in account previous observations in attempt to unravel further analyze changes in $\beta$-LG antigenicity. Thus, aggregation and conformation of $\beta$-LG subjected to DHPM were evaluated in relation to the antigenicity of $\beta$-LG.

In this study, the DLS and AFM data suggested that the $0.1 \mathrm{MPa}$-treated $\beta$-LG samples were aggregated. Almost all of the results about the changes of conformation obtained using different methods indicate a 2-state process (Figure 6a). At the lower DHPM pressures, disaggregation of $\beta-\mathrm{LG}$ samples was accompanied by partial unfolding of the molecule, which was reflected in the decrease in particle size, increase of free $\mathrm{SH}$ and $\beta$-strand contents, and slight exposure of aromatic amino acid residues. With higher pressures, the reaggregation of $\beta-\mathrm{LG}$ could react by way of a thiol-catalyzed S-S bond interchange to form larger aggregates, reflected by the increase in particle size, the formation of aggregates, decrease of $\mathrm{SH}$ and $\beta$-strand contents, and slight changes of conformation around aromatic amino acid residues.

Figure $6 \mathrm{~b}$ showed a model that aggregation and conformational changes of $\beta$-LG were accompanied by a change in epitopes. The antigenicity of the $\beta$-LG depends on the epitopes, which are widely spread along the 162 AA (Clement et al., 2002) and throughout the $\beta$-LG conformation (Sélo et al., 1999b). The best

Table 1. Effect of dynamic high-pressure microfluidization on the content (\%) of $\beta$-LG secondary structures

\begin{tabular}{lcccc}
\hline $\begin{array}{l}\text { Pressure } \\
(\mathrm{MPa})\end{array}$ & $\alpha$-Helix & $\beta$-Strands & Turns & Unordered \\
\hline 0.1 & $14.3 \pm 0.30^{\mathrm{a}}$ & $33.2 \pm 0.25^{\mathrm{a}}$ & $21.8 \pm 0.40^{\mathrm{a}}$ & $30.6 \pm 0.51^{\mathrm{a}}$ \\
40 & $16.3 \pm 0.26^{\mathrm{b}}$ & $35.3 \pm 0.45^{\mathrm{b}}$ & $20.9 \pm 0.55^{\mathrm{ad}}$ & $27.5 \pm 0.50^{\mathrm{b}}$ \\
80 & $11.2 \pm 0.26^{\mathrm{c}}$ & $38.4 \pm 0.40^{\mathrm{c}}$ & $18.4 \pm 0.51^{\mathrm{b}}$ & $32.0 \pm 0.70^{\mathrm{c}}$ \\
120 & $14.0 \pm 0.41^{\mathrm{a}}$ & $37.0 \pm 0.46^{\mathrm{d}}$ & $20.1 \pm 0.65^{\mathrm{d}}$ & $29.0 \pm 0.40^{\mathrm{d}}$ \\
160 & $17.2 \pm 0.40^{\mathrm{d}}$ & $32.2 \pm 0.40^{\mathrm{a}}$ & $22.1 \pm 0.60^{\mathrm{a}}$ & $28.4 \pm 0.40^{\mathrm{bd}}$ \\
\hline
\end{tabular}

${ }^{\mathrm{a}-\mathrm{d}}$ Different letters denote significant differences across different treatments $(P \leq 0.05)$. 


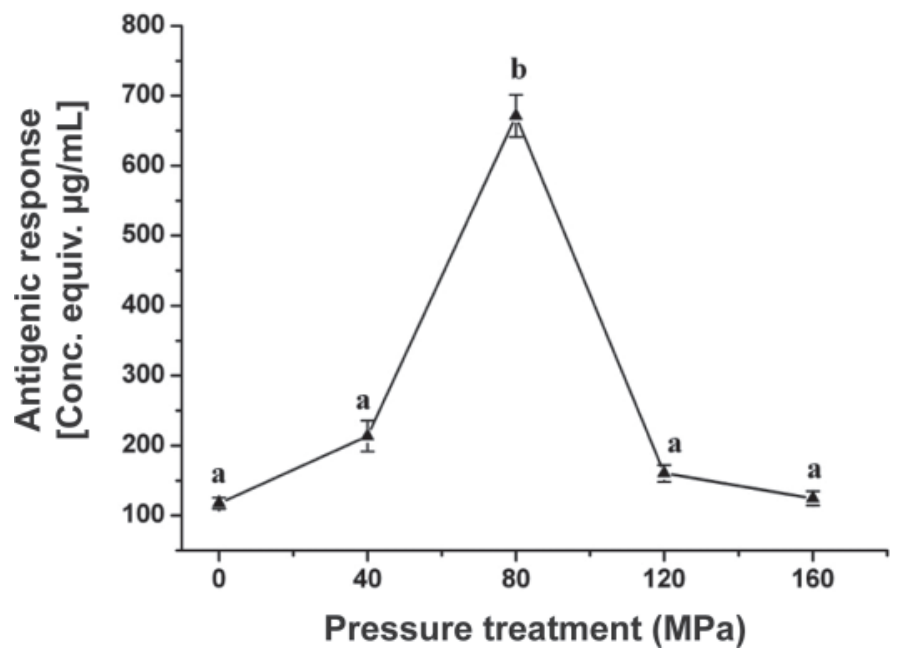

Figure 5. Effect of dynamic high-pressure microfluidization treatment pressure $(0.1,40,80,120$, and $160 \mathrm{MPa}$ for 3 pass, respectively) on antigenicity of $\beta$-LG standard. ${ }^{\mathrm{a}, \mathrm{b}}$ Different letters denote significant differences across different treatments $(P \leq 0.05)$. Adapted using data from the study by Zhong et al. (2011). recognized epitopes, by more than $90 \%$ of allergic individuals, were fragments AA102-124, AA41-60, and AA149-162. The peptides AA41-60 and AA102-124 form a protruding loop between $\beta$-strands $\mathrm{C}$ and $\mathrm{D}$ on the surface of the molecule (Wal, 2001). Those peptides forming the protruding loop may be buried inside the aggregates of $\beta$-LG. The free thiol (Cys 121) of $\beta$-LG was included inside fragment AA102-124. Some epitopes (e.g., AA149-162, AA8-25, and AA84-100) were inside the $\beta$-LG molecule, which included some aromatic side-chains. In addition, the $\beta$-sheets of $\beta$-LG contain some epitopes, particularly 2 very conformation-sensitive epitopes (Clement et al., 2002).

As shown in Figure $6 \mathrm{~b}$, when the free $\mathrm{SH}$ and $\beta$-strand contents increased with a slight exposure of aromatic amino acid residues induced by the disaggregation of aggregates and the partial unfolding of the molecule, some hidden epitopes were possibly exposed and became accessible to bind to the antibodies. Thus, the disaggregation and the partial unfolding changes of $\beta$-LG may contribute to the increase in $\beta$-LG antige-

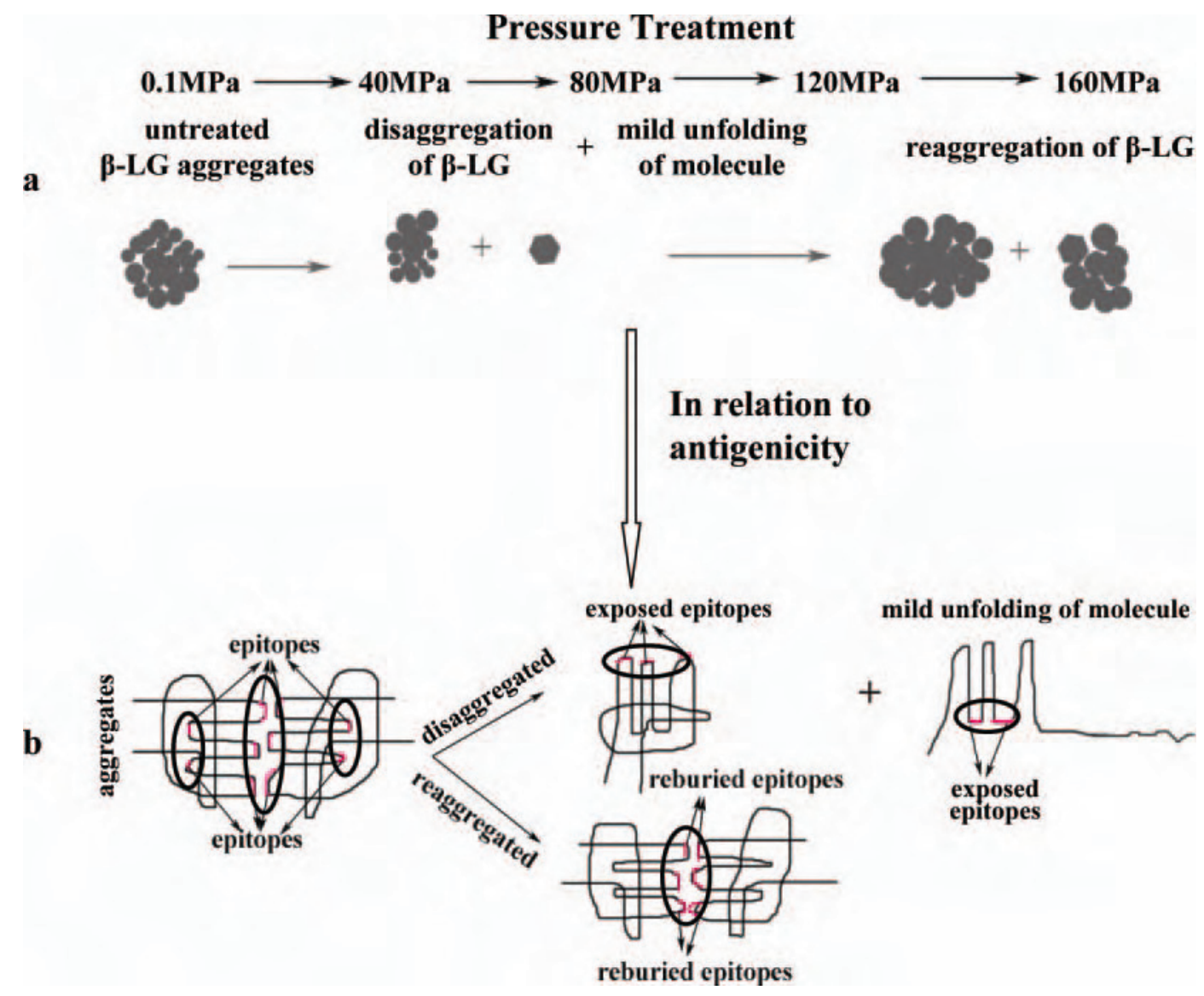

Figure 6. The mechanism of disaggregation and reaggregation of $\beta-\mathrm{LG}$ and a proposed process of the changes in epitopes during disaggregation and reaggregation of $\beta$-LG. Color version available in the online PDF. 
nicity. However, reaggregation of $\beta$-LG may cause the surface-exposed conformational epitopes to be masked. For example, with decreasing SH content, the epitope AA102-124 may be buried. The decrease of the $\beta$-strand contents and the slight conformational changes around aromatic AA residues may also contribute to rebury the epitopes in the $\beta$-LG. In addition, conformational epitopes AA41-60 and AA102-124 were stabilized by disulfide bonds in the native state (Kleber et al., 2004). When the protein is reaggregated by $\mathrm{SH} / \mathrm{S}-\mathrm{S}$ interchange reactions, it may mask those potential antigenic epitopes on the surface of the molecule, and thus, result in the decline of the antigenicity.

\section{CONCLUSIONS}

In this study, we investigated aggregation and conformational changes of $\beta-\mathrm{LG}$ subjected to DHPM in relation to the antigenicity of $\beta-\mathrm{LG}$. At lower pressures, the disaggregation of $\beta-\mathrm{LG}$ samples was accompanied by partial unfolding of the molecule, reflected in the decrease in particle size, increase of free $\mathrm{SH}$ and $\beta$-strand contents, and in slight exposure of aromatic AA residues. Those changes were related to the increase of $\beta-L G$ antigenicity. At higher pressures, the reaggregation of $\beta$-LG could react by way of a thiol-catalyzed disulfide bond interchange to form larger aggregates, which were reflected by increases of particle size, the formation of aggregates, decreases of $\mathrm{SH}$ and $\beta$-strand contents, and slight changes of conformation around aromatic AA residues. Those changes may contribute to the decrease of antigenicity. $\beta$-Lactoglobulin has affinity for many hydrophobic molecules and may interact with other molecules of the milk or whey, and one area of focus will be to study the effect of the interaction between $\beta-\mathrm{LG}$ and other molecules of milk or whey on antigenicity. Although DHPM can influence the antigenicity of $\beta-\mathrm{LG}$, the antigenicity changes during digestion and enzymolysis also needed to be investigated further. Finally, further research is needed on the antigenicity changes of $\beta-\mathrm{LG}$ when using other methods in combination with DHPM.

\section{ACKNOWLEDGMENTS}

This study was supported financially by the National Natural Science Foundation of China (31071573), the Research Program of Sate Key Laboratory of Food Science and Technology, Nanchang University (SKLF-MB-201004), and the Research Fund for the Doctoral Program of Higher Education of China (20103601110002).

\section{REFERENCES}

Ametani, A., T. Sakurai, Y. Katakura, S. Kuhara, H. Hirakawa, T. Hosoi, S. I. Dosako, and S. Kaminogawa. 2003. Amino acid residue substitution at T-cell determinant-flanking sites in beta-lactoglobulin modulates antigen presentation to $\mathrm{T}$ cells through subtle conformational change. Biosci. Biotechnol. Biochem. 67:1507-1514.

Aymard, P., T. Nicolai, D. Durand, and A. Clark. 1999. Static and dynamic scattering of beta-lactoglobulin aggregates formed after heat-induced denaturation at $\mathrm{pH}$ 2. Macromolecules 32:25422552 .

Chang, C. T., C. S. C. Wu, and J. T. Yang. 1978. Circular dichroic analysis of protein conformation - Inclusion of beta-turns. Anal. Biochem. 91:13-31.

Chen, W. L., M. T. Hwang, C. Y. Liau, J. C. Ho, K. C. Hong, and S. J. T. Mao. 2005. Beta-lactoglobulin is a thermal marker in processed milk as studied by electrophoresis and circular dichroic spectra. J. Dairy Sci. 88:1618-1630.

Clement, G., D. Boquet, Y. Frobert, H. Bernard, L. Negroni, J. M. Chatel, K. Adel-Patient, C. Creminon, J. M. Wal, and J. Grassi. 2002. Epitopic characterization of native bovine beta-lactoglobulin. J. Immunol. Methods 266:67-78.

de la Hoz, L., and F. M. Netto. 2008. Structural modifications of beta-lactoglobulin subjected to gamma radiation. Int. Dairy J. 18:1126-1132

Divsalar, A., A. A. Saboury, F. Ahmad, and A. A. Moosavi-Movahedi. 2009. Effects of temperature and chromium (III) ion on the structure of bovine beta-lactoglobulin A. J. Braz. Chem. Soc. 20:1782-1789.

Ellman, G. L. 1959. Tissue sulfhydryl groups. Arch. Biochem. Biophys. 82:70-77.

Feijoo, S. C., W. W. Hayes, C. E. Watson, and J. H. Martin. 1997. Effects of Microfluidizer technology on Bacillus licheniformis spores in ice cream mix. J. Dairy Sci. 80:2184-2187.

Funtenberger, S., E. Dumay, and J. C. Cheftel. 1997. High pressure promotes beta-lactoglobulin aggregation through $\mathrm{SH} / \mathrm{S}-\mathrm{S}$ interchange reactions. J. Agric. Food Chem. 45:912-921.

Grar, H., H. Kaddouri, H. Gourine, H. Negaoui, O. Kheroua, and D. Saidi. 2009. Microwave irradiation under different $\mathrm{pH}$ conditions induced a decrease in beta-lactoglobulin antigenicity. Eur. Food Res. Technol. 229:779-783.

Gulzar, M., T. Croguennec, J. Jardin, M. Piot, and S. Bouhallab. 2009. Copper modulates the heat-induced sulfhydryl/disulfide interchange reactions of beta-lactoglobulin. Food Chem. 116:884891.

Jarvinen, K. M., P. Chatchatee, L. Bardina, K. Beyer, and H. A. Sampson. 2001. IgE and IgG binding epitopes on alpha-lactalbumin and beta-lactoglobulin in cow's milk allergy. Int. Arch. Allergy Immunol. 126:111-118.

Kehoe, J. J., G. E. Remondetto, M. Subirade, E. R. Morris, and A. Brodkorb. 2008. Tryptophan-mediated denaturation of beta-lactoglobulin A by UV irradiation. J. Agric. Food Chem. 56:47204725 .

Kelly, S. M., and N. C. Price. 2000. The use of circular dichroism in the investigation of protein structure and function. Curr. Protein Pept. Sci. 1:349-384.

Kheadr, E. E., J. F. Vachon, P. Paquin, and I. Fliss. 2002. Effect of dynamic high pressure on microbiological, rheological and microstructural quality of Cheddar cheese. Int. Dairy J. 12:435-446.

Kleber, N., and J. Hinrichs. 2007. Antigenic response of beta-lactoglobulin in thermally treated bovine skim milk and sweet whey. Milchwissenschaft 62:121-124.

Kleber, N., I. Krause, S. Illgner, and J. Hinrichs. 2004. The antigenic response of beta-lactoglobulin is modulated by thermally induced aggregation. Eur. Food Res. Technol. 219:105-110.

Kleber, N., S. Maier, and J. Hinrichs. 2007. Antigenic response of bovine beta-lactoglobulin influenced by ultra-high pressure treatment and temperature. Innov. Food Sci. Emerg. Technol. 8:39-45.

Lanciotti, R., C. Chaves-Lopez, F. Patrignani, A. Paparella, M. E. Guerzoni, A. Serio, and G. Suzzi. 2004. Effects of milk treatment 
with dynamic high pressure on microbial populations, and lipolytic and proteolytic profiles of Crescenza cheese. Int. J. Dairy Technol. $57: 19-25$

Liu, C. M., J. Z. Zhong, W. Liu, Z. C. Tu, J. Wan, X. F. Cai, and X. Y. Song. 2011. Relationship between functional properties and aggregation changes of whey protein induced by high pressure microfluidization. J. Food Sci. 76:E341-E347.

Liu, W., J. H. Liu, C. M. Liu, Y. J. Zhong, W. L. Liu, and J. Wan. 2009a. Activation and conformational changes of mushroom polyphenoloxidase by high pressure microfluidization treatment. Innov. Food Sci. Emerg. Technol. 10:142-147.

Liu, W., J. H. Liu, M. Y. Xie, C. M. Liu, W. L. Liu, and J. Wan. 2009b. Characterization and high-pressure microfluidization-induced activation of polyphenoloxidase from Chinese pear (Pyrus pyrifolia Nakai). J. Agric. Food Chem. 57:5376-5380.

Manderson, G. A., L. K. Creamer, and M. J. Hardman. 1999. Effect of heat treatment on the circular dichroism spectra of bovine betalactoglobulin A, B, and C. J. Agric. Food Chem. 47:4557-4567.

Matsumoto, T. 2011. Mitigation of the allergenic activity of beta-lactoglobulin by electrolysis. Pediatr. Allergy Immunol. 22:235-242.

Matsuura, J. E., and M. C. Manning. 1994. Heat-induced gel formation of beta-lactoglobulin - A study on the secondary and tertiary structure as followed by circular-dichroism spectroscopy. J. Agric. Food Chem. 42:1650-1656.

Monahan, F. J., J. B. German, and J. E. Kinsella. 1995. Effect of $\mathrm{pH}$ and temperature on protein unfolding and thiol-disulfide interchange reactions during heat-induced gelation of whey proteins. J. Agric. Food Chem. 43:46-52.

Moroni, O., J. Jean, J. Autret, and I. Fliss. 2002. Inactivation of lactococcal bacteriophages in liquid media using dynamic high pressure. Int. Dairy J. 12:907-913.

Oboroceanu, D., L. Z. Wang, A. Brodkorb, E. Magner, and M. A. E. Auty. 2010. Characterization of beta-lactoglobulin fibrillar assembly using atomic force microscopy, polyacrylamide gel electrophoresis, and in situ Fourier transform infrared spectroscopy. J. Agric. Food Chem. 58:3667-3673.

Paquin, P. 1999. Technological properties of high pressure homogenizers: The effect of fat globules, milk proteins, and polysaccharides. Int. Dairy J. 9:329-335.
Peyron, S., J. Mouecoucou, S. Fremont, C. Sanchez, and N. Gontard. 2006. Effects of heat treatment and pectin addition on beta-lactoglobulin allergenicity. J. Agric. Food Chem. 54:5643-5650.

Ptitsyn, O. B. 1995. Molten globule and protein folding. Adv. Protein Chem. 47:83-229.

Sava, N., I. Van der Plancken, W. Claeys, and M. Hendrickx. 2005. The kinetics of heat-induced structural changes of beta-lactoglobulin. J. Dairy Sci. 88:1646-1653.

Sélo, I., G. Clement, H. Bernard, J. M. Chatel, C. Creminon, G. Peltre, and J. M. Wal. 1999a. Allergy to bovine beta-lactoglobulin: Specificity of human IgE to tryptic peptides. Clin. Exp. Allergy 29:1055-1063.

Sélo, I., G. Clement, H. Bernard, J. M. Chatel, C. Creminon, G. Peltre, and J. M. Wal. 1999b. Allergy to bovine beta-lactoglobulin: Specificity of human IgE to tryptic peptides. Clin. Exp. Allergy 29:1055-1063.

Shibayama, N. 2008. Circular dichroism study on the early folding events of beta-lactoglobulin entrapped in wet silica gels. FEBS Lett. 582:2668-2672.

Tunick, M. H., D. L. Van Hekken, P. H. Cooke, P. W. Smith, and E. L. Malin. 2000. Effect of high pressure microfluidization on microstructure of mozzarella cheese. Lebenson. Wiss. Technol. $33: 538-544$.

Wal, J. M. 2001. Structure and function of milk allergens. Allergy $56: 35-38$.

Wal, J. M. 2002. Cow's milk proteins/allergens. Ann. Allergy Asthma Immunol. 89:3-10.

Yang, J., A. K. Dunker, J. R. Powers, S. Clark, and B. G. Swanson. 2001. Beta-lactoglobulin molten globule induced by high pressure. J. Agric. Food Chem. 49:3236-3243.

Zheng, H., X. Q. Shen, G. H. Bu, and Y. K. Luo. 2008. Effects of pH, temperature and enzyme-to-substrate ratio on the antigenicity of whey protein hydrolysates prepared by Alcalase. Int. Dairy J. 18:1028-1033.

Zhong, J., C. Liu, W. Liu, X. Cai, Z. Tu, and J. Wan. 2011. Effect of dynamic high-pressure microfluidization at different temperatures on the antigenic response of bovine $\beta$-lactoglobulin. Eur. Food Res. Technol. 233:95-102. 